\title{
A POSSIBLE INTERPRETATION OF THE APPARENT INTER- FERENCE ACROSS THE CENTROMERE FOUND BY CALLAN AND MONTALENTI IN CULEX PIPIENS
}

\author{
By A. R. G. OWEN \\ Department of Genetics, Combridge
}

\section{INTRODUCTORY}

Received 25.iii.49

Callan and Montalenti (1947), in a study of the mosquito Culex pipiens, found evidence of an apparent chiasma interference operating between the arms of bivalents at meiosis. They concluded from counting of types of bivalents that chiasma interference functions across the centromere in chromosomes of this organism. It is possible, however, to interpret their chiasma statistics in a rather different way. It is possible to get a good fit to the distribution of bivalent types observed by Callan and Montalenti, on the assumption that chiasma interference (in the usual sense) does not act through or across the centromere. This can be done if we assume that the first chiasma to be formed in a chromosome pair, being a necessity for bivalent formation (and therefore an essential prerequisite for subsequent chiasmata), is not on an equal footing with the chiasmata formed later. It is shown here that this hypothesis of a primary chiasma gives a legitimate explanation of the observations of Callan and Montalenti on both Culox pipiens and Theobaldia longiareolata Macq.

\section{THE OBSERVATIONS OF CALLAN AND MONTALENTI}

Three pairs of chromosomes were found in Culex. Two pairs (M) are equal in their apparent physical lengths, and are about $\mathrm{I} \frac{1}{2}$ times as long as the third pair $(m)$. All six chromosomes have median centromeres. Though the physical length of arm seems comparable with that of other mosquito species (e.g. Theobaldia), the Culex chromosomes are "short" in respect of chiasma formation, since :-

(i) Mean chiasma frequency per arm of bivalent is less than two-thirds.

(ii) The proportion of bivalents with more than one chiasma on either arm is very small $(\mathrm{I} \cdot 74$ per cent.).

Leaving these latter bivalents out of account, Callan and Montalenti counted the numbers of bivalents (both $\mathrm{M}$ and $m$ ) in the three classes $\mathrm{O} / \mathrm{O}, \mathrm{O} / \mathrm{X}, \mathrm{X} / \mathrm{X}$. $(\mathrm{O} / \mathrm{O}$ denotes the univalent pairs, $\mathrm{O} / \mathrm{X}$ denotes bivalents with one chiasma, and $\mathrm{X} / \mathrm{X}$ denotes bivalents 
with one chiasma in each arm.) The percentage in these three classes (copied from their paper) are given in table I.

For each specimen a smaller proportion of $\mathrm{X} / \mathrm{X}$ bivalents was found than would be expected on the assumptions of statistical independence between arms, and an equal initial probability of a chiasma appearing in either arm.

For four of the specimens, the bivalents ( $M$ chromosomes only) which showed at least one chiasma (i.e. types $\mathrm{O} / \mathrm{X}, \mathrm{X} / \mathrm{X}$ ) were further classified according to the scheme $\mathrm{O} / \mathrm{P}, \mathrm{O} / \mathrm{D}, \mathrm{P} / \mathrm{P}, \mathrm{P} / \mathrm{D}, \mathrm{D} / \mathrm{D}$. (Here $\mathrm{O}$ denotes absence of chiasmata from one arm, $\mathrm{P}$ the presence of a chiasma in a proximal region of an arm, D the presence of a distal chiasma.) Table 2 is taken from the paper of Callan and Montalenti and shows the percentages in each of these five classes.

Callan and Montalenti interpreted these figures as implying :-

(i) The presence of a chiasma on one arm tends to inhibit formation of a chiasma on the other arm.

(ii) A proximal chiasma on one arm has a greater inhibitory effect on the chiasma in the other arm than has a distal chiasma.

(iii) A chiasma on either arm tends to "repel" a chiasma formed on the other.

That is to say, the observations were taken to imply that in Culex the centromere is not effective as an insulator between arms in respect of chiasma interference. Culex differs, therefore, from Theobaldia, in which the observed frequencies of bivalent types were in accordance with those to be expected if the arms were independent.

\section{INTERPRETATION IN TERMS OF AN OBLIGATORY CHIASMA}

The conclusions derived from their data by Callan and Montalenti depend on the assumption that the two chiasmata observed on the same bivalent are on entirely the same footing: i.e. each has the same initial probability as the other, but when formed diminishes the probability (conditional on its own presence) of the other being formed, to a value less than the initial probability of formation of the latter, had the former not been established.

If this be granted, then their conclusions follow.

However, it has sometimes been suggested that the first chiasma to be formed has a rather different status from its successors. The first chiasma, on this view, may be called obligatory or primary since it is essential for proper synapsis and disjunction to take place. If it be formed, then other chiasmata may follow on the same bivalent. If it be not formed, a bivalent is not constituted by the pair of chromosomes concerned, and further chiasmata will not be established.

On this view we might expect that, as a result of evolutionary modification, the initial probability " $p$ " that this first, obligatory, 
chiasma be formed on the chromosome pair would have achieved a high value; perhaps in the range $0 \cdot 90-1 \cdot 0$. And indeed the figures in table I agree well with this line of thought. They imply that the probability that at least one chiasma be set up on a given pair is precisely in this range.

Proceeding with this argument, it does not seem necessary to assume that when the primary chiasma has been established, the probability $q$, conditional on that obligatory chiasma, of a second chiasma appearing in the other arm should be the same as the initial probability of the first one being established. If $q<p$ then it is easily seen that there will be apparent interference between chiasmata on different arms, for it is not possible by inspection to distinguish between the primary chiasma and the secondary one when both are present. In this interpretation of the data, the primary chiasma can hardly be said to interfere with the establishment of the secondary because it is a necessary prerequisite for the existence of the latter.

To argue more precisely, let it be assumed :-

(i) The arms are identical in length and properties.

(ii) In all circumstances chiasma interference operates within each arm to such an extent that the probability of two chiasmata in one arm is negligible.

(iii) A first chiasma is essential for bivalent formation and has the probabilities $p, \mathrm{I}-p$ of being or not being formed. Suppose that it has the probabilities $p p_{1}, p p_{2}$ of occurring proximally or distally.

Under these conditions, when a primary chiasma has been formed in either arm, then by (i) and (ii), a secondary chiasma can be formed only in the other arm. Suppose :-

(iv) The secondary chiasma occurs or does not occur with probabilities $q, \mathrm{I}-q$ independent of the position in its own arm of the primary chiasma, and that it may occur proximally or distally with respective probabilities $q_{1}, q_{2}$ independent of the position of the first chiasma.

Clearly $p_{1}+p_{2}=\mathrm{I}, q_{1}+q_{2}=q$. The classes $\mathrm{O} / \mathrm{O}, \mathrm{O} / \mathrm{X}, \mathrm{X} / \mathrm{X}$ have relative frequencies $\mathrm{I}-p, p(\mathrm{I}-q), p q$. The classes $\mathrm{O} / \mathrm{P}, \mathrm{O} / \mathrm{D}$, $\mathrm{P} / \mathrm{P}, \mathrm{P} / \mathrm{D}, \mathrm{D} / \mathrm{D}$ occur with relative frequencies $p_{1}\left(\mathrm{r}-q_{1}-q_{2}\right)$, $p_{2}\left(\mathrm{I}-q_{1}-q_{2}\right), p_{1} q_{1}, p_{2} q_{1}+p_{1} q_{2}, p_{2} q_{2}$. If $a, 2 b, c$ are the observed numbers in the classes $\mathrm{O} / \mathrm{O}, \mathrm{O} / \mathrm{X}, \mathrm{X} / \mathrm{X}$ the maximum likelihood estimators of $p$ and $q$ are simply the ratios

$$
\hat{p}=\frac{a+2 b}{a+2 b+c}, \hat{q}=\frac{a}{a+2 b} .
$$

These are given in table 1 , being calculated from the percentage values $a /(a+2 b+c)$, etc., given by Callan and Montalenti. These estimated values, of course, give an exact fit to their percentage data. 
A more severe test of the present hypothesis consists in finding values $p_{1}, p_{2}, q_{1}, q_{2}$ which will give a good fit when used to reconstruct the percentages in table 2. This can be done quite successfully.

TABLE I

\begin{tabular}{|c|c|c|c|c|c|}
\hline \multirow{2}{*}{ Specimen no. } & \multirow{2}{*}{$\mathrm{O} / \mathrm{O}$} & \multirow{2}{*}{$\mathrm{O} / \mathrm{X}$} & \multirow{2}{*}{$\mathrm{X} / \mathrm{X}$} & \multicolumn{2}{|c|}{$\begin{array}{l}\text { Estimated probabilities } \\
\text { (percentages) }\end{array}$} \\
\hline & & & & $p$ & $q$ \\
\hline $\begin{array}{r}1 \\
2 \\
3 \\
4 \\
5 \\
6 \\
7 \\
8 \\
9 \\
10\end{array}$ & $\begin{array}{r}9 \cdot 09 \\
32 \cdot 58 \\
35.08 \\
26 \cdot 55 \\
36 \cdot 51 \\
22 \cdot 97 \\
25 \cdot 00 \\
19.81 \\
18.08 \\
18 \cdot 77\end{array}$ & $\begin{array}{l}86 \cdot 36 \\
64 \cdot 25 \\
63 \cdot 74 \\
73 \cdot 23 \\
63 \cdot 49 \\
70 \cdot 27 \\
75 \cdot 00 \\
80 \cdot 18 \\
80 \cdot 14 \\
80 \cdot 06\end{array}$ & $\begin{array}{l}4 \cdot 55 \\
3 \cdot 17 \\
1 \cdot 17 \\
0 \cdot 21 \\
0 \cdot 00 \\
6 \cdot 76 \\
0 \cdot 00 \\
0 \cdot 00 \\
1 \cdot 77 \\
1 \cdot 17\end{array}$ & $\begin{array}{r}95 \cdot 45 \\
96 \cdot 83 \\
98 \cdot 82 \\
99 \cdot 78 \\
100 \cdot 00 \\
93 \cdot 24 \\
100 \cdot 00 \\
99 \cdot 99 \\
98 \cdot 22 \\
98.83\end{array}$ & $\begin{array}{r}9 \cdot 52 \\
33 \cdot 65 \\
35 \cdot 50 \\
26 \cdot 61 \\
36 \cdot 51 \\
24 \cdot 64 \\
25 \cdot 00 \\
19 \cdot 81 \\
18 \cdot 41 \\
18 \cdot 99\end{array}$ \\
\hline
\end{tabular}

TABLE 2

\begin{tabular}{|c|c|c|c|c|c|}
\hline Specimen no. & $\mathrm{O} / \mathrm{P}$ & $\mathrm{O} / \mathrm{D}$ & $\mathrm{P} / \mathrm{P}$ & $\mathrm{P} / \mathrm{D}$ & $\mathrm{D} / \mathrm{D}$ \\
\hline $\begin{array}{r}2 \\
4 \\
9 \\
10\end{array}$ & $\begin{array}{l}13.02 \\
26 \cdot 45 \\
21 \cdot 92 \\
20 \cdot 35\end{array}$ & $\begin{array}{l}47 \cdot 95 \\
48 \cdot 06 \\
56 \cdot 68 \\
56 \cdot 64\end{array}$ & $\begin{array}{l}0.68 \\
0.32 \\
0.00 \\
0.44\end{array}$ & $\begin{array}{r}10 \cdot 95 \\
8 \cdot 39 \\
6 \cdot 4^{2} \\
3 \cdot 54\end{array}$ & $\begin{array}{l}27 \cdot 39 \\
16 \cdot 77 \\
14.97 \\
19 \cdot 03\end{array}$ \\
\hline
\end{tabular}

Denoting by $n_{1}, n_{2}, n_{3}, n_{4}, n_{5}$, the observed percentages in the five classes $\mathrm{O} / \mathrm{P}, \mathrm{O} / \mathrm{D}, \mathrm{P} / \mathrm{P}, \mathrm{P} / \mathrm{D}, \mathrm{D} / \mathrm{D}$, the maximum likelihood estimators of $p_{1}, p_{2}, q_{1}, q_{2}$, are (appendix) $\hat{p}_{1}=n_{1}+n_{3}+n_{4}-\Delta ; \hat{p}_{2}=n_{2}+n_{5}+\Delta$; $\hat{q}_{1}=n_{3}+\Delta ; \hat{q}_{2}=n_{4}+n_{5}-\Delta$ where $\Delta=n_{4} p_{2} q_{1} /\left(p_{2} q_{1}+p_{1} q_{2}\right)$, so that $\Delta$ is a root of a certain cubic. A good approximation to $\Delta$ is

$$
\frac{n_{3} n_{4}\left(n_{2}+n_{5}\right)}{n_{3}\left(n_{2}+n_{5}\right)+\left(n_{1}+n_{3}+n_{4}\right)\left(n_{4}+n_{5}\right)-n_{4} \overline{\left(n_{2}+n_{3}+n_{5}\right)}}
$$

Table 3 gives the estimates for the four specimens, together with the observed percentages and expected percentages calculated with these estimates.

The fit in each case is good. The smallness of the class $\mathrm{P} / \mathrm{P}$ makes a $\chi^{2}$ test of fit rather unreliable on a total of about 200 (which is roughly the size of the counts made by Callan and Montalenti). However, the $\chi^{2}$ values calculated on a total of 200 are

$\begin{array}{ccc}\text { Specimen } & \chi_{[1]}^{2} & \text { Probability } \\ 2 & 0.1 \text { I } 8 & >0.7 \\ 4 & 0.3554 & \bumpeq 0.6 \\ 9 & 0.0502 & >0.8 \\ \text { I0 } & 3.5834 & \bumpeq 0.17\end{array}$


The present hypothesis is therefore not significantly contradicted by the data, and as far as the Culex data can take us, it is admissible as an alternative explanation of the results, though at present more than this could not legitimately be claimed for it.

TABLE 3

\begin{tabular}{|c|c|c|c|c|c|c|c|c|c|c|c|}
\hline \multirow{2}{*}{ Spec. no. } & & \multirow{2}{*}{$\mathrm{O} / \mathrm{P}$} & \multirow{2}{*}{$\mathrm{O} / \mathrm{D}$} & \multirow{2}{*}{$\mathrm{P} / \mathrm{P}$} & \multirow{2}{*}{$\mathrm{P} / \mathrm{D}$} & \multirow{2}{*}{$\mathrm{D} / \mathrm{D}$} & \multicolumn{5}{|c|}{ Estimated probabilities } \\
\hline & & & & & & & $p_{1}$ & $p_{2}$ & $q_{1}$ & $q_{2}$ & $q$ \\
\hline 2 & $\begin{array}{l}\text { Obs. } \\
\text { Exp. }\end{array}$ & $\begin{array}{r}\times 3.02 \\
12.94\end{array}$ & $\begin{array}{l}47.95 \\
48.09\end{array}$ & $\begin{array}{l}0.68 \\
0.87\end{array}$ & $\begin{array}{l}10.95 \\
10.64\end{array}$ & $\begin{array}{l}27 \cdot 39 \\
27 \cdot 54\end{array}$ & $\begin{array}{c}2 \mathrm{I} \cdot 23 \\
\ldots\end{array}$ & $\begin{array}{c}78 \cdot 87 \\
\ldots\end{array}$ & $\begin{array}{c}4 \cdot 10 \\
\ldots\end{array}$ & $\begin{array}{c}34.92 \\
\ldots\end{array}$ & $\begin{array}{c}39.02 \\
\ldots\end{array}$ \\
\hline 4 & $\begin{array}{l}\text { Obs. } \\
\text { Exp. }\end{array}$ & $\begin{array}{l}26 \cdot 45 \\
25.84\end{array}$ & $\begin{array}{l}48 \cdot 06 \\
48 \cdot 68\end{array}$ & $\begin{array}{l}0.32 \\
0.28\end{array}$ & $\begin{array}{l}8 \cdot 39 \\
9 \cdot 08\end{array}$ & $\begin{array}{l}16 \cdot 77 \\
16 \cdot 12\end{array}$ & $\begin{array}{c}34 \cdot 67 \\
\ldots\end{array}$ & $\begin{array}{c}63 \cdot 33 \\
\ldots\end{array}$ & $\begin{array}{c}0 \cdot 8 \mathrm{I} \\
\ldots\end{array}$ & $\begin{array}{c}24 \cdot 67 \\
\ldots\end{array}$ & $\begin{array}{c}25 \cdot 4^{8} \\
\ldots\end{array}$ \\
\hline 9 & $\begin{array}{l}\text { Obs. } \\
\text { Exp. }\end{array}$ & $\begin{array}{l}21 \cdot 92 \\
22 \cdot 28\end{array}$ & $\begin{array}{l}56 \cdot 68 \\
56 \cdot 3^{2}\end{array}$ & $\begin{array}{l}0.00 \\
0.00\end{array}$ & $\begin{array}{l}6 \cdot 4^{2} \\
6 \cdot 19\end{array}$ & $\begin{array}{l}14.97 \\
15.33\end{array}$ & $\begin{array}{c}28 \cdot 34 \\
\ldots\end{array}$ & $\begin{array}{c}7 \mathrm{I} \cdot 66 \\
\ldots\end{array}$ & $\begin{array}{c}0.00 \\
\ldots\end{array}$ & $\begin{array}{c}21 \cdot 39 \\
\ldots\end{array}$ & $\begin{array}{c}2 \mathrm{I} \cdot 39 \\
\quad \ldots\end{array}$ \\
\hline 10 & $\begin{array}{l}\text { Obs. } \\
\text { Exp. }\end{array}$ & $\begin{array}{l}20 \cdot 35 \\
18 \cdot 44\end{array}$ & $\begin{array}{l}56 \cdot 64 \\
58 \cdot 55\end{array}$ & $\begin{array}{l}0.44 \\
0: 20\end{array}$ & $\begin{array}{l}3.54 \\
5.94\end{array}$ & $\begin{array}{l}19.03 \\
16.88\end{array}$ & $\begin{array}{c}23.95 \\
\ldots\end{array}$ & $\begin{array}{c}76 \cdot 05 \\
\ldots\end{array}$ & $\begin{array}{c}0.82 \\
\ldots\end{array}$ & $\begin{array}{c}22 \cdot 19 \\
\cdots\end{array}$ & $\begin{array}{c}23 \cdot 01 \\
\ldots\end{array}$ \\
\hline
\end{tabular}

\section{DISAPPEARANCE OF APPARENT INTERFERENCE WITH INCREASING ARM LENGTH}

It has been shown that on the theory of a primary chiasma apparent interference is to be expected between arms, even if the centromere in fact operates as an insulator. The same theory has the merit of reconciling with one another the observations made by Callan and Montalenti on Culex pipiens and I heobaldia longiareolata, without assuming any essential difference between these two species, other than effective "length" in respect to chiasma frequencies. This is because, on quite general grounds, we may expect that the effect will be noticeable only in the case of very "short" chromosome arms as in Culex. Even if the phenomenon of the primary chiasma occurs, the spurious transcentromeric interference will rapidly attenuate as arm length is increased. On the present theory, therefore, the difference between Culex and Theobaldia consists only in the difference in arm length as defined in terms of mean chiasma frequency.

Let $p$ be the probability of a primary chiasma being set up, so that $p$ is the frequency of chromosome pairs containing at least one chiasma ; i.e. the frequency of bivilent pairs.

Let now $q$ be the probability (conditional on the presence of the primary chiasma) of there being at least one chiasma in the arm not containing the primary. Then the classes: (a) univalent pairs, (b) bivalent pairs, $(c)$ bivalents with chiasmata on both arms have the relative frequencies : $1-p, p, p q$.

We may expect that when the arms are "long," $p$ approximates to unity, and $q$ has a much larger value than in Culex pipiens. $q$ probably becomes almost as great as $p$. Hence in long-armed species the negative 
correlation between chiasma numbers on the two arms tends to vanish. If it is desired to have a formal measure of the apparent interference, a suitable index can be defined in terms of a quantity analogous to the coefficient of genetical coincidence. We may take as index

$$
\mathrm{I}=\mathrm{I}-\mathrm{C}
$$

where $\mathrm{C}=\frac{\text { frequency of bivalents with chiasmata on both arms }}{{\text { (frequency of bivalents })^{2}}^{2}}$

$$
=p q /(p)^{2}=q \mid p \text {. }
$$

Thus $\mathrm{I}=\mathrm{I}-q / p=\frac{p-q}{p}$.

On long arms we expect $q \rightarrow p \rightarrow \mathrm{I}, \mathrm{C} \rightarrow \mathrm{I}$, and $\mathrm{I} \rightarrow \mathrm{o}$.

It is altogether likely that the phenomenon, if it does exist, will rarely be noticed. Even if it should be universal, it will be very difficult to observe except in extraordinary species such as Culex pipiens. In normal species it is impossible to determine whether a primary chiasma is involved or not unless the data are very extensive. This can be well illustrated by analysing the data on Theobaldia in the light of the rival hypotheses.

\section{ANALYSIS OF DATA ON THEOBALDIA LONGIAREOLATA MACQ.}

In Theobaldia longiareolata Macq., Callan and Montalenti found three pairs of chromosomes, in many respects similar to those in Culex pipiens. Two pairs (M) are of approximately equal length and with approximately median centromeres. The third pair $(m)$ is shorter in physical length, and has a much lower mean frequency of chiasma formation, in this resembling the chromosomes of Culex. The mean chiasma frequency per arm in the $M$ bivalents was $1 \cdot 456$. The first two columns of table 4 show the types of $\mathrm{M}$ bivalents observed, and the frequencies of these types, and are taken from table ro of Callan and Montalenti's paper.

Let A stand for the hypothesis of a primary chiasma. Let B denote the assumption that the first chiasmata to be formed on the two arms are on the same footing. In each case the centromere is supposed to act as an insulator.

The expected values for the class frequencies as calculated by Callan and Montalenti on hypothesis B, are given in column 3 of table 4. On this hypothesis the argument is as follows :-The arms are identical and independent. Considering a single arm, the probabilities of its containing o, I, 2, 3 chiasmata are respectively I $-r, r_{1}, r_{2}, r_{3}$ where $r_{1}+r_{2}+r_{3}=r$. The expected class frequencies and the estimators of $r_{1}, r_{2}, r_{3}$ and $r$ are given in appendix II. The values obtained are $r_{1}=52 \cdot 65$ per cent., $r_{2}=42 \cdot 35$ per cent., $r_{3}=2.94$ per cent., $r=97.94$ per cent. These values reproduce the expectations calculated by Callan and Montalenti. 
Applying hypothesis $\mathrm{A}$ the argument is :-The relative frequencies of univalent pairs and bivalent pairs are $\mathrm{I}-p$ and $p$, where $p$ is the probability of formation of the primary chiasma. $\frac{1}{2} p$ is the probability of the primary chiasma appearing on a particular arm. Let $\frac{1}{2} p p_{1}$, $\frac{1}{2} p p_{2}, \frac{1}{2} p p_{3}$, where $p_{1}+p_{2}+p_{3}=\mathrm{I}$, be the respective probabilities of the primary chiasma appearing on a particular arm alone, or with one other chiasma, or with two other chiasmata.

TABLE 4

\begin{tabular}{|l|c|c|c|}
\hline \multicolumn{1}{|c|}{ Class } & Observed & $\begin{array}{c}\text { Expected on } \\
\text { hypothesis B }\end{array}$ & $\begin{array}{c}\text { Expected on } \\
\text { hypothesis A }\end{array}$ \\
\hline O/O & & & \\
O/X & 0 & $0 \cdot 07$ & $0 \cdot 00$ \\
O/XX & 5 & $3 \cdot 69$ & $4 \cdot 14$ \\
O/XXX & 2 & $2 \cdot 96$ & $2 \cdot 45$ \\
X/X & 0 & $0 \cdot 20$ & $0 \cdot 41$ \\
X/XX & 51 & $47 \cdot 12$ & $46 \cdot 39$ \\
XXXX & 69 & $75 \cdot 80$ & $77 \cdot 45$ \\
XX/XX & 3 & $5 \cdot 25$ & $4 \cdot 61$ \\
XX/XXX & 33 & $30 \cdot 48$ & $29 \cdot 57$ \\
XXX/XXX & 7 & $4 \cdot 23$ & $4 \cdot 98$ \\
& 0 & $0 \cdot 15$ & $0 \cdot 00$ \\
\hline
\end{tabular}

Let $\mathrm{I}-q$, and $q$ be the probabilities (conditional on the existence of a primary in one arm) of the non-appearance or appearance of at least one chiasma in the other arm. Let $q_{1}, q_{2}, q_{3}$, where $q_{1}+q_{2}+q_{3}=q$, be the conditional probabilities of there being exactly I, 2 or 3 secondaries on this other arm. Then the expectations are as given in appendix II. Applying the estimation formulæ given there to the data, we get as estimators of the parameters

$$
\begin{array}{ll}
\hat{p}_{1}=0.329,4 \mathrm{I} 2+\Delta & \hat{q}_{1}=0.723,529 \\
\hat{p}_{2}=0.6 \mathrm{II}, 765-\Delta & \hat{q}_{2}=0.235,294 \\
\hat{p}_{3}=0.058,824 & \hat{q}_{3}=0.0 \\
\hat{p}=\mathrm{I} \cdot 000,00 \mathrm{I} & \hat{q}=0.958,823
\end{array}
$$

where $\Delta$ is the relevant root of

$$
2 \Delta^{3}-\text { I I I } 76,470 \Delta^{2}+0 \cdot 290,935 \Delta-0 \cdot 03 \text { I } 460=0 .
$$

By trial it is found that, correct to four figures, $\Delta=0.2622$ Consequently

$$
\begin{array}{lll}
\hat{p}_{1}=59 \cdot 16 \text { per cent. } & \hat{q}_{1}=46 \cdot 13 \text { per cent. } \\
\hat{p}_{2}=34 \cdot 96 \quad, & \hat{q}_{2}=49 \cdot 75 \quad, \\
\hat{p}_{3}=5.88 \quad, & \hat{q}_{3}=0.00 \quad, \\
\hat{p}=100 \cdot 00 \quad,, & \hat{q}=95.88 \quad,
\end{array}
$$

It may be noted, incidentally, that these values satisfy the relations $\hat{r}_{i}=\frac{1}{2}\left(\hat{p}_{i}+\hat{q}_{i}\right), \quad \hat{r}=\frac{1}{2}(\hat{p}+\hat{q})$. The corresponding expectations are given in column 4 of table 4 . They are seen to give what is, on the 
whole, about as good a fit to the observations as do those calculated on hypothesis B. The small classes are reproduced with almost consistently greater accuracy, but the large class numbers are more divergent on $\mathrm{A}$ than on $\mathrm{B}$, though the discrepancies are in the same directions as those arising on hypothesis $\mathbf{B}$. In so far as a $\chi^{2}$ test is applicable or informative we have :-

On hypothesis $\mathrm{A} \chi_{[3]}^{2}=3.8322, \mathrm{Pr}=0.28$,

On hypothesis $B \chi_{[6]}^{2}=5 \cdot$ I I I $2, \operatorname{Pr}>0.50$.

Glearly no decision between hypotheses could legitimately be made, since neither is significantly better than the other.

The formal index of interference between arms (as defined in section 4) is zero on hypothesis $\mathrm{B}$, and $0.04 \mathrm{I} 2$ on hypothesis A.

In passing it may be noted that on the basis of the $r$ values (or of the mean $p$ and $q$ values) the intensity of chiasma interference, as defined by Haldane (I93I), has the value

$$
\text { I }-\frac{\text { variance of } m}{\text { mean of } m}=0.76 \mathrm{I}
$$

(where $m$ is the number of chiasmata per arm), which is of quite the usual order of magnitude. Hence the $\mathrm{M}$ chromosomes of Theobaldia appear to be perfectly typical ones in respect of chiasma frequency and intensity of chiasma interference. The present discussion shows therefore that the quasi-interference due to a primary chiasma is likely to be quite invisible in typical chromosomes, and could only wake itself apparent in abnormally "short" chromosomes like those of Culex.

Appendix 1

\section{ESTIMATION OF PARAMETERS FOR CULEX}

We have

\begin{tabular}{lccccc} 
& $\mathrm{O} / \mathrm{P}$ & $\mathrm{O} / \mathrm{D}$ & $\mathrm{P} / \mathrm{P}$ & $\mathrm{P} / \mathrm{D}$ & $\mathrm{D} / \mathrm{D}$ \\
Observed & $\mathrm{N} n_{1}$ & $\mathrm{~N} n_{2}$ & $\mathrm{~N} n_{3}$ & $\mathrm{~N} n_{4}$ & $\mathrm{~N} n_{5}$ \\
Expected & $\mathrm{p}_{1}\left(\mathrm{I}-q_{1}-q_{2}\right)$ & $p_{2}\left(\mathrm{I}-q_{1}-q_{2}\right)$ & $p_{1} q_{1}$ & $p_{2} q_{1}+p_{1} q_{2}$ & $p_{2} q_{2}$ \\
& \multicolumn{7}{c}{ (multiplied by N $p)}$.
\end{tabular}

Since $p_{1}+p_{2}=\mathrm{I}$, the function to be maximised is

$$
\begin{gathered}
\mathrm{N} n_{1} \log p_{1}\left(\mathrm{I}-q_{1}-q_{2}\right)+\mathrm{N} n_{2} \log p_{2}\left(\mathrm{I}-q_{1}-q_{2}\right)+\mathrm{N} n_{3} \log p_{1} q_{1} \\
+\mathrm{N} n_{4} \log \left(p_{2} q_{1}+p_{1} q_{2}\right)+\mathrm{N} n_{5} \log p_{2} q_{2}-\mathrm{N} \lambda\left(p_{1}+p_{2}\right) .
\end{gathered}
$$

Therefore the estimators satisfy

$$
\begin{aligned}
& n_{1}+n_{3}+\frac{n_{4} p_{1} q_{2}}{p_{2} q_{1}+p_{1} q_{2}}=\lambda p_{1} ;-\frac{\left(n_{1}+n_{2}\right) q_{1}}{\mathrm{I}-q_{1}-q_{2}}+n_{3}+\frac{n_{4} p_{2} q_{1}}{p_{1} q_{1}+p_{1} q_{2}}=0 \\
& n_{2}+n_{5}+\frac{n_{4} p_{2} q_{1}}{p_{2} q_{1}+p_{1} q_{2}}=\lambda p_{2} ;-\frac{\left(n_{1}+n_{2}\right) q_{1}}{\mathrm{I}-q_{1}-q_{2}}+n_{5}+\frac{n_{4} p_{1} q_{2}}{p_{1} q_{2}+p_{2} q_{1}}=0 \\
& \quad \lambda=n_{1}+n_{2}+n_{3}+n_{4}+n_{5}=\mathrm{I} \\
& \quad \hat{q}=\hat{q}_{1}+\hat{q}_{2}=n_{3}+n_{4}+n_{5} .
\end{aligned}
$$

which give

and 
Putting

we get

$$
\Delta=n_{4} p_{2} q_{1} /\left(p_{2} q_{1}+p_{1} q_{2}\right)
$$

$$
\begin{aligned}
p_{1} & =n_{1}+n_{3}+n_{4}-\Delta, & p_{2} & =n_{2}+n_{5}+\Delta, \\
q_{1} & =n_{3}+\Delta & q_{2} & =n_{4}+n_{5}-\Delta .
\end{aligned}
$$

Substituting in (I), $\Delta$ is found to satisfy a cubic, of which the relevant root is approximately equal to

$$
\Delta=\frac{n_{3} n_{4}\left(n_{2}+n_{5}\right)}{n_{3}\left(n_{2}+n_{5}\right)+\left(n_{1}+n_{3}+n_{4}\right)\left(n_{4}+n_{5}\right)-n_{4}\left(n_{2}+n_{3}+n_{5}\right)} .
$$

This value can be rapidly improved by iteration.

\section{Appendix II}

\section{ESTIMATION OF PARAMETERS FOR THEOBALDIA}

\section{Hypothesis A: primary chiasma}

The normalised class frequencies are :-

\begin{tabular}{lcl} 
Class & Observed & \multicolumn{1}{c}{ Expected } \\
$\mathrm{O} / \mathrm{O}$ & $n_{1}$ & $\mathrm{I}-p$ \\
$\mathrm{O} / \mathrm{X}$ & $n_{2}$ & $p p_{1}(\mathrm{I}-q)$ \\
$\mathrm{O} / \mathrm{XX}$ & $n_{3}$ & $p p_{2}(\mathrm{I}-q)$ \\
$\mathrm{O} / \mathrm{XXX}$ & $n_{4}$ & $p p_{3}(\mathrm{I}-q)$ \\
$\mathrm{X} / \mathrm{X}$ & $n_{5}$ & $p p_{1} q_{1}$ \\
$\mathrm{X} / \mathrm{XX}$ & $n_{6}$ & $p\left(p_{1} q_{2}+p_{2} q_{1}\right)$ \\
$\mathrm{X} / \mathrm{XXX}$ & $n_{7}$ & $p\left(p_{1} q_{3}+p_{3} q_{1}\right)$ \\
$\mathrm{XX} / \mathrm{XX}$ & $n_{8}$ & $p p_{2} q_{3}$ \\
$\mathrm{XX} / \mathrm{XXX}$ & $n_{9}$ & $p\left(p_{2} q_{3}+p_{3} q_{2}\right)$ \\
$\mathrm{XXX} / \mathrm{XXX}$ & $n_{10}$ & $p p_{3} q_{3}$
\end{tabular}

where $p_{1}+p_{2}+p_{3}=\mathrm{I}$ and $q=q_{1}+q_{2}+q_{3}$. The function to be maximised is

$$
n_{1} \log (\mathrm{I}-p)+n_{2} \log p p_{1}(\mathrm{I}-q)+\ldots-\lambda\left(p_{1}+p_{2}+p_{3}\right) .
$$

The estimators satisfy

$$
\begin{aligned}
& \frac{n_{1}}{\mathrm{I}-p}=\frac{\sum_{2}^{10} n_{i}}{p} \\
& \begin{cases}\lambda p_{1} & =n_{2}+n_{5} \quad+\Delta_{2}+\Delta_{3} \\
\lambda p_{2} & =n_{3}+n_{6}+n_{8}+\Delta_{1}-\Delta_{3} \\
\lambda p_{3} & =n_{4}+n_{7}+n_{9}+n_{10}-\Delta_{1}-\Delta_{2}\end{cases} \\
& \left\{\begin{array}{lll}
\left(n_{2}+n_{3}+n_{4}\right) \frac{q_{1}}{\mathrm{I}-q}=n_{5}+n_{6}+n_{7} & & -\Delta_{2}-\Delta_{3} \\
\left(n_{2}+n_{3}+n_{4}\right) \frac{q_{2}}{\mathrm{I}-q}=n_{8}+n_{9} & -\Delta_{1}+\Delta_{3} \\
\left(n_{2}+n_{3}+n_{4}\right) \frac{q_{3}}{\mathrm{I}-q}=n_{10} & +\Delta_{1}+\Delta_{3}
\end{array}\right.
\end{aligned}
$$

where $\quad \Delta_{1}=\frac{n_{9} p_{2} q_{3}}{p_{2} q_{3}+p_{3} q_{2}}, \quad \Delta_{2}=\frac{n_{7} p_{1} q_{3}}{p_{1} q_{3}+p_{3} q_{1}}, \quad \Delta_{3}=\frac{n_{6} p_{1} q_{2}}{p_{1} q_{2}+p_{2} q_{1}}$ 
Therefore

$$
\begin{aligned}
& \lambda=\mathrm{I}-n_{1}, \quad \hat{q}=\sum_{5}^{10} n_{i} \div\left(\mathrm{I}-n_{1}\right) \\
& \begin{aligned}
\left\{\begin{array}{l}
\left(\mathrm{I}-n_{1}\right) \hat{p}_{1}=n_{2}+n_{5} \\
\left(\mathrm{I}-n_{1}\right) \hat{p}_{2}=n_{3}+n_{6}+n_{8}+\Delta_{2}+\Delta_{3} \\
\left(\mathrm{I}-n_{1}\right) \hat{p}_{3}=n_{4}+n_{7}+n_{9}+n_{10}-\Delta_{1}-\Delta_{2}
\end{array}\right. \\
\left\{\begin{array}{lr}
\left(\mathrm{I}-\Delta_{1}\right) \hat{q}_{1}=n_{5}+n_{6}+n_{7} & -\Delta_{2}-\Delta_{3} \\
\left(\mathrm{I}-n_{1}\right) \hat{q}_{2}=n_{8}+n_{9} & -\Delta_{1}+\Delta_{3} \\
\left(\mathrm{I}-n_{1}\right) \hat{q}_{3}=n_{10} & +\Delta_{1}+\Delta_{3}
\end{array}\right.
\end{aligned}
\end{aligned}
$$

If $n_{1}$ and $n_{10}$ are zero, then the solution is

$$
\begin{aligned}
& \left\{\begin{array}{l}
\hat{p}_{1}=n_{2}+n_{5}+\Delta \\
\hat{p}_{2}=n_{3}+n_{6}+n_{8}-\Delta \\
\hat{p}_{3}=n_{4}+n_{7}+n_{9}
\end{array}\right. \\
& \left\{\begin{array}{l}
\hat{q}_{1}=n_{5}+n_{6}+n_{7}-\Delta \\
\hat{q}_{2}=n_{8}+n_{9}+\Delta \\
\hat{q}_{3}=0
\end{array}\right.
\end{aligned}
$$

where $\Delta_{1}=\Delta_{2}=0, \Delta_{3}=\Delta$, and $\Delta$ satisfies the cubic

$$
\begin{aligned}
& 2 \Delta^{3}+\Delta^{2}\left(n_{2}-n_{3}-3 n_{6}-n_{7}+n_{9}\right) \\
&+\Delta\left[\left(n_{2}+n_{5}\right)\left(n_{8}+n_{9}\right)+\right.\left.\left(n_{3}+n_{6}+n_{8}\right)\left(n_{5}+n_{6}+n_{7}\right)-n_{6}\left(n_{2}+n_{5}+n_{8}+n_{9}\right)\right] \\
&-n_{6}\left(n_{2}+n_{5}\right)\left(n_{8}+n_{9}\right)=0
\end{aligned}
$$

which is easily solved by trial.

\section{Hypothesis B : chiasmata on equal footing}

The normalised class frequencies are :-

O/O
$0 / X$
$0 / X X$
$0 / X X X$
$X / X$
$X / X X$
$X / X X X$
$X X / X X$
$X X / X X X$
$X X X / X X X$

$n_{1}$
$n_{2}$
$n_{3}$
$n_{4}$
$n_{5}$
$n_{6}$
$n_{7}$
$n_{8}$
$n_{9}$
$n_{10}$

$$
\begin{aligned}
& (\mathrm{I}-r)^{2} \\
& 2 r_{1}(\mathrm{I}-r) \\
& 2 r_{2}(\mathrm{I}-r) \\
& 2 r_{3}(\mathrm{I}-r) \\
& r_{1}^{2} \\
& 2 r_{1} r_{2} \\
& 2 r_{1} r_{3} \\
& r_{2}^{2} \\
& 2 r_{2} r_{3} \\
& r_{3}{ }^{2}
\end{aligned}
$$

where

$$
r_{1}+r_{2}+r_{3}=r \text {. }
$$

The estimators are :-

$$
\begin{aligned}
& \hat{r}_{1}=\frac{1}{2}\left(n_{2}+2 n_{5}+n_{6}+n_{7}\right) \\
& \hat{r}_{2}=\frac{1}{2}\left(n_{3}+n_{6}+2 n_{8}+n_{9}\right) \\
& \hat{r}_{3}=\frac{1}{2}\left(n_{4}+n_{7}+n_{9}+2 n_{10}\right) \\
& \hat{r}=\mathrm{I}-n_{1}-\frac{1}{2}\left(n_{2}+n_{3}+n_{4}\right) .
\end{aligned}
$$
Since

These are in a simple relation to the estimators under hypothesis A.

$$
\hat{r}_{i}=\left(1-n_{1}\right) \frac{1}{2}\left(\hat{p}_{i}+\hat{q}_{i}\right),(i=1,2,3) .
$$




\section{SUMMARY}

It is shown that the observations of Callan and Montalenti are not only consistent with the hypotheses advanced by these writers, namely :- chiasma interference operates across the centromere in Culex pipiens, but is confined to the interior of each arm in the chromosomes of Theobaldia longiareolata: but may also be explained with equal legitimacy on the hypothesis that a primary chiasma is formed with a high probability, and that subsequent chiasmata are conditional on its existence and are not on the same footing as the primary.

It is shown that when the centromere acts as an interference insulator, the occurrence of the primary chiasma has the effect of an apparent chiasma interference between arms. The effect is marked in "short" chromosomes, but is very much less in arms of normal length. In the latter case it is almost imperceptible.

On the present data this explanation can only be put forward as a possible alternative to the explanation in terms of real interference. It has, however, the slight advantage of representing an economy of hypotheses. It requires that the chromosomes of Culex pipiens be exceptional only in respect of the low mean frequency of chiasmata per arm of bivalent, and not exceptional both in this respect, and in that of having a centromere transparent to chiasma interference.

\section{REFERENCES}

CALlAN, H. G., AND MONTALENTI, G. 1947.

Chiasma interference in mosquitos.

7. Genet., 48, 1 19-136.

HALDANE, J. B. S. 1931 .

The cytological basis of genetical interference.

Cytologia, 3, 54 . 